\title{
Adapting building design to access by individuals with
} intellectual disability

L. Castell (Department of Construction Management, Curtin University of Technology, Perth, Western Australia)

\begin{abstract}
Over the last 15 years, since introduction of the Disability Discrimination Act (DDA) (Commonwealth Government of Australia, 1992), there has been much discussion about the extent and nature of building access for the disabled, particularly in response to proposed revisions to the Building Code of Australia (BCA) and the introduction of a Premises Standard covering building access. Much of the argument which contributed to the two year delay in submitting a final version of these documents for government approval related to the extent of access provisions and the burden of cost. The final version submitted to government by the Australian Building Codes Board (ABCB) (not released publicly) appears to still contain inconsistencies between the DDA and the $B C A$ in several areas such as wayfinding and egress.
\end{abstract}

In the debate preceding submission of the final version there appears to have been little reference to access requirements for individuals with intellectual disability (ID). This may be due to a general lack of research on the topic. Consequently, this paper uses a combination of the knowledge gained from a limited number of previous wayfinding studies, literature describing general problems faced by those with ID and the author's personal experience observing others with ID to create a list of probable difficulties and suggested solutions. The paper concludes with a discussion about the associated cost implications and benefits in providing the required access.

Keywords: Intellectual disability, access to premises, building regulation, discrimination, wayfinding

\section{INTRODUCTION}

Although there may be ongoing debate, the DDA is quite clear that, with only minor exceptions buildings must provide equitable access. Whilst much has been done through the BCA to aid building access for those with physical and/or sensory disability there is very little attention paid to understanding or incorporating the access needs of those with ID. The draft Premises Standard and associated BCA along with Australian Standards all contain, and rightly so, detailed specifications for the design of facilities for the physically and/or sensory disabled including width of corridors, height of benches, space requirements for wheelchairs, colour differentiation, signage and tactile surfaces to aid the blind and hearing loops to aid the deaf. However, an investigation of those same documents reveals that there is no mention of ID (Castell 2006). This is really surprising considering that ABS statistics (Australian Bureau of Statistics, 2004) show there are almost twice as many persons with ID as vision impaired (VI) in Australia who would be capable of independently visiting and using a building. It also means that buildings designed in accordance with the BCA may not be meeting the full requirements of the DDA.

Something needs to be done, yet there is only limited research in this crucial area to describe what is required for equitable access. Because there is such a shortage of relevant research it is necessary to find alternative means of defining the problem. Apart from the three wayfinding projects described below the paper uses a combination of general literary commentaries about problems associated with ID along with the author's personal experience observing others with ID to create a list of probable difficulties and suggested solutions. Having established a potential scope for the problem, the paper concludes with a discussion about the associated cost implications and benefits in providing such building access.

\section{EXTENT OF RELEVANT LITERATURE}

The author in previous research (Castell 2006) undertook an extensive survey of literature to find details of any case studies or research that had been undertaken about access to buildings by individuals with ID. Only a few relevant studies were 
found, the major ones of which are briefly described below:

a) Mencap evaluation (date to be circa 2003) Unpublished, described in DRC document

Mencap organised various site visits with a group of people with a learning disability to evaluate accessibility.

b) Salmi and others (2004) - Conference paper

This study examined and assessed environmental features that cued wayfinding behaviour for 13 persons with mild intellectual disabilities (ID) and compared these results with the wayfinding behaviour of 10 persons from the general population (comparison group).

c) Disability Rights Commission (2004a) Report

The research team undertook a literature search, evaluated examples of existing practice aimed at learning disability, held seven focus groups around Great Britain with people with a learning disability and worked with people with a learning disability to evaluate signs in 'real-world' situations.

d) Office of the Deputy Prime Minister (2006a) - Report

The research team undertook a literature survey, held telephone interviews and workshops with people with learning disabilities and described two case studies about wayfinding.

\section{e) Salmi (2007) - PhD research}

The researcher recorded wayfinding comments from students who visited a shopping mall and a county government centre building in Minneapolis and then observed ten people with ID wayfinding through the two buildings.

There are several other research projects that have observed participants during wayfinding, but not specifically about those with ID. The knowledge from these studies may be transferable, but only indirectly. The author also acknowledges that the above-mentioned survey could never be considered exhaustive and therefore some research projects may not have been highlighted by the research search terms used or from the databases surveyed and therefore not described here. If this is the case, the author would welcome any additional information to add to the body of knowledge and to help refine the following list. There may also be some highly localised case studies or exercises that have been undertaken for building projects that were never written up or published. Again the author would welcome details of these studies.

\section{EFFECTS OF ID ON BUILDING ACCESS AND SOME POSSIBLE DESIGN SOLUTIONS}

The process of accessing a building, navigating through it to a given destination and then retracing the process to leave the building is called wayfinding. To be able to successfully wayfind through a building a person needs to learn "spatial characteristics in either an on-route or distant environment using only information perceived and memorized while traveling" (Golledge 2003). The ability to understand and use wayfinding information involves cognitive processing and much has been written about how this occurs and how it affects wayfinding (Golledge 1999, 2003; Golledge, Parnicky \& Rayner 1979; Passini et al. 1998). However, ID is a form of cognitive impairment that affects a person's capacity to process information. As a result they will have greater difficulty in obtaining and processing the required wayfinding information. The extent to which this occurs depends largely on the etiology of ID. This is a complex subject warranting ongoing research beyond the scope of this current paper. This paper focuses on the practical consequences of cognitive impairment rather than the process itself.

Building design needs to incorporate features that will aid wayfinding for the ID. It needs to give assistance to both the obtaining and the processing of information. The discussion below has separated these two activities but, in reality, they will be repeated over and over again as the person progresses through the building. Each section commences with a general commentary about the difficulties ID can pose for the process and then offers suggestions how building designs might be altered to accommodate access by those with ID.

\section{ACTIVITY 1: OBTAINING INFORMATION}

Wayfinding for a person with ID can be a complicated and frustrating process. They may not understand that information needs to be gathered in order to navigate the building, and even if they do they may not know where or how to find it. This can lead to frustration and disappointment if 
they have to abandon the process. An inability to remain focussed on the task or impatience because it is taking too long can also be reasons to abandon wayfinding. They can have the added frustration in trying to communicate their needs to others who either can't be bothered to or who are just simply unable to understand their request. Their reading skills may be insufficient to understand written directions and their interpretive skills may not allow them to understand meanings in the symbols or signs they see.

The following list describes aspects of building design that can affect the ID person's ability to obtain information and suggests how these aspects may be improved.

\section{Signs}

Signs are a major component of any wayfinding system. Their logical layout, clarity, continuity and consistency are fundamental to finding the required destination (Disability Rights Commission 2004a). Many in the general population, however, have difficulty in eliciting the right information from signs (Nelson 2004) and for those with ID, rather than supporting wayfinding, the signs may cause confusion (Disability Rights Commission 2004a). Poor use of colour, text, imagery and terminology in signage can make wayfinding very difficult. As an example a hospital might use two different terms, "XRay department" and "Radiology Department", on different signs to direct patients to the same location. Another example highlighted in a Mencap exercise in UK (Disability Rights Commission, 2004a) showed some signs directing people to the 'way out' and others to the 'exit'. Inconsistency in the style of signs across various buildings on the same site has been noted as a problem for those with ID by Nelson (2004) although, as he suggests, it is unlikely that any single system could be made to suit all users. Nonetheless, a lack of standardised symbols for use in specific building types means that users can become disoriented when confronted with a completely new and unfamiliar symbol system. Signs may convey confusing information to someone with an ID. The ODPM report (Office of the Deputy Prime Minister, 2006a) describes an example where a sign directs users to rooms 36-40 which does not convey to a person with ID that this also includes rooms 37, 38 and 39. People with ID also have a tendency to interpret information on signs literally. For instance a sign which is intended to indicate that a library is straight ahead shows an arrow pointing upwards, leading the person with ID to look upwards despite the library not actually being overhead. Using an upward pointing arrow may be acceptable to the general population who can interpret the message, but it can give confusing information to a person with ID. The sign designer has assumed that all users of the sign will see it the way they do. To be effective, therefore, signs should be clear, concise and consistent (Nelson 2004).

\section{a) Clear}

Signs should use an appropriate typeface, have sufficiently large text and have good colour contrast (but not combinations such as red on pink or silver on grey). Colour can also be used to help project meaning such as red on a fire exit sign (Disability Rights Commission 2004a) Pictures on signs can help people with ID particularly if they have difficulty relating words to mental images. Carefully chosen and readily identifiable symbols may be appropriate. Signs need to be placed at an appropriate height so that they can be read and in a location that avoids glare or reflections that could confuse or distract. One site visited by the author had signs positioned over a reception area in such a way that reflections from nearby lighting made the sign unreadable. Someone had taken the time to place the sign but failed to check that it was usable.

\section{b) Concise}

Words and/or graphics and symbols must project the required information with the minimum of fuss. Lengthy explanations and/or combinations of photos, symbols or text can lead to confusion. A photograph has been found to help some people with ID where the photograph shows a familiar subject linked to the purpose of the sign (Office of the Deputy Prime Minister 2006a)

\section{c) Consistent}

Colour can be used in directional signage to differentiate different areas of a building, but once chosen must remain consistent. The placement of signs should be consistent, being located where signs would be expected on a regular basis.

There are some comprehensive sign design guides that have been produced to assist in achieving the above aims, for instance the Sign Design Guide (Fraser \& Barker 2000) and "Am I making myself 
clear" (Mencap 2007a). In summary, good signage is a matter of common sense. It takes only a few minutes to stand back and critically assess whether it actually informs the reader about what they need to know.

\section{Maps}

The use of maps requires a capacity to process two-dimensional information and relate it to a three-dimensional world. Authors such as Golledge (2003) have written extensively on this topic and have described how the process occurs in general. However, due to limited cognitive processing capability, persons with ID will find map reading a complex, difficult and sometimes impossible task. The Disability Rights Commission in UK undertook a series of surveys with learning disabled persons about their ability to wayfind in the built environment (Disability Rights Commission 2004a). They found that maps were problematic and confusing because they presented too much information. Research by Salmi (2007), in which she observed persons with ID wayfinding in a shopping mall in USA, found that participants could understand the purpose of a map but not how to use the information it contained. As a result, Salmi (2007) suggests that maps should be less cluttered, contain a "you are here" locator, relate only to the floor they serve in a multi-storey building, identify key facilities such as toilets using recognisable symbols, use colour as a reinforcer (but not primary cue) and be designed to avoid glare from the map's surface. She also suggests that maps could be enhanced with speech technology triggered when the person with ID states where they want to go or lights a route line on the map to show how to access the requested location. However, this still requires the user to have a level of cognition to be able to interpret two-dimensional information into a three-dimensional environment.

\section{Directories}

Building directories present similar problems. Directories provide detailed and potentially complex information which may be beyond the understanding of a person with ID. Salmi's research (2007) identified that directories require skill to decode or read which may be beyond the capacity of a person who only had rudimentary reading skills. To improve directories for use by people with ID they must be uncomplicated, in readable text, in good contrasting colours, well lit without glare and have meaningful information. Colour could be used to direct the person to different floor or building locations (although it is important to remember that a proportion of the population will have problems differentiating colours).

\section{Timetables}

In a survey of members, the UK-based organisation Mencap (2007b) found that understanding timetables was the most common problem for people in using transport. Whilst this may relate to public transport facilities rather than buildings, it is pertinent to this paper because buildings will display opening times often at the entrance to the building (i.e. a shop's opening hours). Not being able to comprehend the information could result in a wasted journey or the person not even being able to access the premises at all. Whilst the general population will understand the information being presented the Mencap survey indicated this was not the case for those with a learning disability (LD). They suggest using big print, readable fonts, concise information and understandable time information (which could perhaps include pictograms of clock faces with the hours drawn on).

\section{Lighting}

Lighting is essential for good accessibility by all users of a building. It will, however, specifically help the ID user read signs, find pathways and feel safe in public spaces. The placement and type of lighting can also be used to help direct users through a building. This is discussed later in the section on wayfinding. The type of light fittings should be carefully chosen to suit the environment in which they are used. For instance, buildings used by autistic children and/or adults should avoid lights that flicker or emit buzzing sounds as these can cause significant and disturbing distractions.

\section{Colour}

Colour has already been mentioned as a factor in the provision of good wayfinding advice. It can be used to enhance and highlight signs, differentiate areas within a building and raise awareness of pertinent features, such as landmarks, within a building. Interestingly research by DSC (Disability Rights Commission 2004a) highlighted that using unfamiliar colours in 
common signs such as fire exits may mean they are misunderstood or missed altogether. This is an important point, particularly when considering the ability of people with ID to exit a building in an emergency. Consistently using internationally recognised colours for warning signs, for instance, could help to reduce misunderstanding, so long as the user can be taught to recognise the significance of those colours.

7. Reception facilities and a human interface

Appropriate location of reception facilities and access to staff is essential for a good wayfinding system. For those with ID a reception counter gives opportunity to ask and obtain specific assistance. However, not all buildings have a reception area and in some cases it may not be adjacent to the building's entrance. Placing a counter on the second floor of a building presents the person with ID with the problem of independently wayfinding to the counter before they can even ask for assistance. Consequently, the design and placement of the counter itself can create a barrier. Salmi (2007) found for instance, that people with ID can be nervous about entering open spaces if they are not familiar with the location. Placing a reception counter in the middle of an open space may, therefore, discourage use by those with ID. Reception counters are also often used to "make a statement" about the building or the occupiers of the building. As a result they may be brightly lit, loud, intimidating or confusing in design all of which could deter the person with ID from approaching staff to ask for directions. Wayfinding systems that rely heavily on reception counter staff to provide assistance may be intimidating for a person with ID who has poor communication skills. Some may be nonverbal, which would significantly reduce the effectiveness of such a wayfinding system. Given their difficulties with cognitive processing, many people with ID will have difficulty in knowing who or what to ask and, even more importantly, in remembering what they have been told.

Good, barrier-free design for people with ID should mean that the location of the reception counter is obvious as soon as a building is entered (Disability Rights Commission 2004a; Office of the Deputy Prime Minister 2006a), that it is not intimidating and is staffed by personnel who a readily identifiable (Salmi 2007) and understand how to help persons with all forms of disability (FACS 2008). Salmi's (2007) observations also highlighted a serious risk for people with ID in that they demonstrated a lack of understanding about who was or was not appropriate to ask for directions.

\section{ACTIVITY 2: PROCESSING INFORMATION}

For a successful wayfinding trip which results in finding a required destination people need to obtain and process environmental information (Golledge, 2003). Whilst the general population may be able to cope with this activity, those with ID may have difficulty with the cognitive processing required. There will be a significant amount of information which needs filtering but they may not be able to identify and comprehend relevant information (Golledge, Parnicky \& Rayner 1979). They may have difficulty in memorizing information for later use in wayfinding such as signs along the route or from a receptionist at the entrance. Reduced short-term memory and limited ability to transfer information from one location to another can also mean that each visit to a building is a completely new challenge. Basically, they can forget where they are and where they want to be (Anonymous 2001). Information processing can also be disturbed for the person with ID, particularly, those with autism (Mitchell \& Ropar 2004) who have an increased sensitivity to noises, light and smells within their immediate surroundings. Some with autism also experience disturbances in the sensory information they receive, to the extent that they see individual parts of a scene before comprehending the full picture. Therefore it takes longer to process and can give inaccurate information. They tend to lose confidence with visual information and may rely on sounds or smells for their wayfinding. A delay in being able to process information can lead to frustration and an increased likelihood of abandoning wayfinding, as found by Salmi (2007) during her observations.

For equitable building access and good wayfinding it is imperative that the building design minimise the difficulties experienced by those with ID. Foresight on the part of the designer can produce a barrier-free building that incorporates use by all persons. Unfortunately, those with 
ID are often overlooked because little is known of their needs. As the following section of this paper identifies, some of the design changes can affect the proposed structure and layout of the building with considerable cost if implemented after construction commences. Getting the design right at the beginning, therefore, is a much better solution. The following section describes some of the difficulties for the person with ID in processing information and offers some suggestions for better design.

\section{Appropriate building layouts}

According to Riley's (08-03-002) research on wayfinding in adults with mental retardation there was evidence that the ability to acquire configurational knowledge may be affected by the size and complexity of the environment to be learned. A bank building, for instance, can be highly confusing to navigate due to the multiple counters for different services (Office of the Deputy Prime Minister, 2006a). Good design, therefore, should ensure that buildings are not confusing (AS1428.1). They should be both legible and predictable - using appropriate internal layouts, information, colour and lighting to convey information on how to navigate a building (Disability Rights Commission, 2003). The layout should provide good sight lines with clearly defined paths (Office of the Deputy Prime Minister 2006a), direct access routes and clear directional signage (Disability Services Commission 2006). The designed layout needs to limit the number of decisions required whilst navigating. In the ODPM commissioned research (Office of the Deputy Prime Minister 2006a) the ID participants clearly preferred to visit buildings that were easy to get round, where you could see where you were going and also see how to get back to the entrance (an issue of considerable importance in terms of means of escape). The research concluded that there should be clearly defined routes with limited numbers of choices, adequate landmark features and easy to find key facilities such as reception counters. Participants in Salmi's (2007) research concurred with this by indicating that spatial knowledge was helpful with wayfinding.

The building layout also needs to consider spatial and location relationships. To some degree all building users learn the consistency in building layout relationships - the position of toilets in a shopping centre, the reception counter in an office building, etc. However, changes in the expected location of such features leads to confusion and greater difficulty in wayfinding (Office of the Deputy Prime Minister 2006a). DRC (2003) suggest that in multi storey buildings it would be preferable to locate facilities in corresponding positions on each floor. Consistency in layout from building to building can also help people transfer wayfinding information (i.e. similar locations for toilets in each building).

\section{Adequate and appropriate wayfinding cues}

Earlier sections of this paper have discussed the design of various wayfinding cues such as signs, colour, etc. This section looks at how these can be used as part of the wayfinding system in a building, their adequacy and appropriateness.

\section{a) Signage}

People with ID can recognise and use signs (Disability Rights Commission 2004a) and by judicial positioning they can help overcome potential language and communication barriers. Salmi (2007) found in her research that signage proved critical for all participants in the study. An absence of signage made the participants frustrated and overwhelmed and lose confidence in their ability to navigate the building. According to CRC for Construction Innovation (2007) signs should be placed in transitional areas to reassure people they are on the correct path. They also suggest that the distance between signs in a long corridor should be no greater than 30 metres, although others interviewed by the author believe this may need to be a lot closer for people with ID in order to reinforce their memory along the way. Salmi (2007) concluded that designers need to improve the amount and quality of signage and recommended that important informational signs should be placed perpendicular to the path of travel. None of these suggestions add unduly to the cost of construction. It is merely good design.

\section{b) Use of landmarks}

Landmarks are features that stand out in an environment. According to Mondschein, Blumenberg, \& Taylor (2005) they are the major feature used in cognitive mapping and can be any notable, relatively stationary point feature. They can be travel decision points, not just destinations 
and are usually the first thing learned from a new environment. They may or may not be specifically designed as landmarks but can quickly become the means of identifying an area or locating oneself in the environment (i.e. a clock tower or a fountain). These have been recognised as important aspects for people with ID in their ability to navigate the interior of a building (Office of the Deputy Prime Minister 2006a) Wayfinding can be much more difficult without prompts such as landmarks (Office of the Deputy Prime Minister 2006a). They can help identify how far along a particular corridor one has travelled and once identified can make a person with ID feel more comfortable (Office of the Deputy Prime Minister 2006a). Landmarks can help them learn the route as they become anchor points in localizing nearby spaces (Passini et al., 2000).

From her research Salmi (2007) recommends that landmarks be distinct (i.e. well-lit, colourful, of unique shape, etc.) and include, if possible, an interactive component such as a phone booth, be linked to directional signage, include features such furnishings to make using them a memorable experience and be appealing to other senses such as sound and not just a visual pointer.

\section{c) Use of colour}

Using colour as a wayfinding device carries the risk that a reasonable number of people have difficulties in identifying colours (i.e. colour blindness). However, judicial use of colour can support directional information. For instance, following a yellow line proved to be very popular to participants in research by DRC (2003) and in research commissioned by the UK ODPM (2006a). Salmi (2007) suggested that colour could be used in conjunction with signage to code directional information.

d) Location for reception counters and other human interfaces

Huelat (2007) identified reception counters as important places to commence the wayfinding process. They should, therefore, be placed in a convenient location close to the point of entry where a person with ID could seek assistance. Reception counters provided opportunity for communication and the obtaining advice which Salmi (2007) found in her case study were frequently used by the participants with ID.

\section{Reduced distractions}

The third and final consideration in achieving a good wayfinding system for those with ID is to ensure the sensory environment is not distracting. Different forms of ID can be affected by distractions such as light, sound and smell. Flickering lights can cause significant discomfort to an autistic person as the distraction makes it too difficult for them to focus on the task at hand. This can also be true for shadows that are reflecting off adjacent surfaces or light reflecting from mirrors, etc. Noisy environments can sometimes make a person with ID uncomfortable and create sufficient distraction to prevent them from concentrating on the wayfinding process (FACS 2008). People with autism can be very sensitive and upset by noise (Harker \& King 2002). It may be as simple as the buzzing from a fluorescent light tube, but it will be enough to completely distract them from the wayfinding process. However, Salmi (2007) found in her study that general noise in the environment did not appear to significantly affect wayfinding capability. Whilst some smells could be considered offensive and off-putting to a person wayfinding, in many cases smell can contribute to the memory of a location, or the feeling or preference for a situation (eg. the smell of baking bread). Consequently, smell could either help or hinder wayfinding depending on the circumstances and the person involved. For instance, in Salmi's research (2007) she found that participants were using odours to remember the location of various features such as restaurants.

\section{POTENTIAL COST IMPLICATIONS}

Cost implications will depend on the timing of the work. Changes that can be made to the design before construction commences are likely to have a much smaller cost impact. Refurbishment and retro-fitting will obviously be more costly. It would be preferable, therefore, to ensure that designers consider the above access considerations at the time they are designing the bulk of the project. Much in the same way as means of escape has become a common consideration, it is hoped that inclusive design for all will become second nature.

The Australian government, in assessing justification for the release of the revised BCA (Draft version 2004), commissioned quantity surveyors to produce costs for the recommended changes and a costing 
document was produced ((Australian Building Codes Board 2004a). Unfortunately, as the proposed revisions excluded wayfinding and contained nothing specifically related to building access for those with ID, there are no detailed costs to discuss. More research needs to be completed on building access for people with ID in order to clarify the precise nature of the changes required (be it signage, layouts, landmarks, etc) so that more detailed costings can be produced.

It seems unlikely that many of the proposed changes would incur significant additional cost, especially if they are implemented at the design stage - a view shared by FACS (2008). Designing legible and meaningful signage, providing accessible routes through a building, adding a coloured line to the corridors, providing recognisable and memorable landmarks (that may also add quality for all users) are unlikely to incur significant expensive. They are all a matter of good and judicious design from the outset. However, too often the needs of disabled people are considered late in the day and are separated from the needs of others (Office of the Deputy Prime Minister, 2006b). As Small (HREOC, 2006) suggests, best practice in building access doesn't have to cost a significant amount, it may not cost much at all if the right decisions are made early on.

What would be troublesome, however, is the compliance cost if a building owner or designer is sued because their building does not comply with the DDA. Architects interviewed as part of previous research by the author expressed concern about their ability to comply with a DDA where there are no specific rules or guidelines to assist them interpret the law (Castell 2006). This was the supposed role of the Premises Standard which for the moment is still awaiting Government approval (HREOC 2007). Unfortunately, even if approval was given to the proposed Standard it still excludes reference to wayfinding issues according to the Australian Building Codes Board (2004b) and, from a reading of the draft BCA which accompanies the Premises Standard, has no direct mention of ID. Given that the suggested review period for the Premises Standard is five years it seems unlikely that it is going to provide guidance to architects relating to building access for those with ID for some time to come.
Industry groups have challenged even the current scope of changes. In a statement on their website, the Property Council of Australia (2004) indicate that the "proposed changes are significant and costly. While the RIS (Regulatory Impact Statement) estimated a cost of $\$ 26$ billion, the Property Council's assessment was that the cost was closer to $\$ 60$ billion over 30 years". They go on to say that they have firmly stated their concerns and encouraged other industry groups to do the same. The chance of obtaining support for future changes to the BCA and Premises Standards to incorporate wayfinding and access issues for people with ID seem rather unlikely in the current climate.

Graeme Innes, Deputy Disability Discrimination Commissioner for HREOC made an interesting point in a speech delivered to the $A B C B$ conference in September 2007 (HREOC 2005). He asked; "...How many of us will be at the $A B C B$ conference in 2025? How many of us will be able to access buildings where only stairs provide for vertical movement, where there are no hearing loops and where signage is inadequate? Age and disability affect everyone - they're as certain as death and taxes. If you, or a member of your family or a close friend don't have a disability now, you can guarantee that will change within the next twenty years". The changes proposed through this paper will not only benefit those with ID, but also benefit those "babyboomers" who, in 20 years time will be suffering Alzheimer's disease or dementia. Problems in wayfinding are similar for people with ID, Alzheimer's disease and dementia. Those currently querying the introduction of a revised BCA will themselves most likely be the beneficiaries of the wayfinding requirements set out in this paper. The "cost" therefore, cannot be seen as financial but must be seen in terms of the social cost for failing to act. As HREOC (2005) commented "...Any cost the Premises Standards may impose is just an investment in the type of society which we all want - one that includes us all".

\section{POTENTIAL BENEFITS}

According to ABCB (2004a) the analysis of expected benefits is, to a substantial degree, qualitative because "... very little substantial progress has been made in developing quantified estimates of the benefits associated with improved access 
to premises. However problems with quantification do not suggest that those benefits are small or unimportant". Providing building access for people with ID is likely to provide the following benefits:

\section{a) It is good for business}

Providing appropriate building access increases the percentage of the population who can access a supplier's goods and services. This means a larger client base for the business, be it retail, food, manufacturing or other services. There are nearly 250,000 people with ID who could independently access business premises if the buildings were fully accessible and this number could be increased considerably by adding their friends and family, all of whom are potential customers (HREOC \& Marrickville Council 2004). The commercial sector is beginning to understand the benefits of providing inclusive environments (Office of the Deputy Prime Minister 2006b) not only for ethical reasons but for good commercial sense. Suggested changes to accommodate building use by people with ID will also improve access for a whole range of other potential customers such as the elderly and those with small children. It is not just about accessibility, however, but also about the environment that a business creates. If a person with ID feels that the business cares about their custom by providing appropriate access, then that person will use and recommend the business to others. In a survey about access to services undertaken by DRC in UK (Disability Rights Commission, 2004b), $70 \%$ of disabled respondents (not just those with ID) reported that their friends and family would consider using alternative services if the particular service wasn't available to their disabled friend/family member. This is a strong indicator of the strength of attitude that access can generate. Rather than losing business for a lack of suitable accessibility, providing access could increase the business turnover. Developments that are inclusive may also have an enhanced market value (Office of the Deputy Prime Minister 2006b) because it means purchasers avoid being exposed to the risk of future compliance costs. Tenants and/or future owners of such premises will also realise that high levels of access will improve participation by the disabled and increase their overall business impact. b) It avoids litigation and subsequent compliance costs

According to the ABCB (2004a) the "degree of compliance with the general duties of the DDA in relation to premises is relatively low". Improving access will, therefore, assist businesses to meet their legal responsibilities and avoid the cost and time involved in defending themselves against future compliance claims (HREOC, 2005). If the American construction industry is any indication, claims for noncompliance are increasing and Australia is likely to follow suit in the future. Considering access requirements at the design stage will avoid such costly litigation (HREOC \& Marrickville Council 2004) and the potentially crippling cost of compliance in an existing building.

\section{c) It provides a benefit to the whole community}

It can contribute to a government's wider social objectives and will reward developers by adding value to their building. (Office of the Deputy Prime Minister 2006b). Providing good access for people with ID will also provide benefits to other members of the community who may be disadvantaged in terms of access such as the elderly, people with temporary disabilities and tourists from linguistically diverse backgrounds who may have difficulty reading signs (Disability Services Commission 2006).

\section{CONCLUSION}

Considerable effort has been expended in seeking the introduction of a Premises Standard and supporting revisions to the BCA. It has taken over seven years so far and there is still no final resolution. The construction industry is still unclear about the requirements to comply with both a BCA and the DDA. Even if the currently proposed Premises Standard is approved there will be areas that have been excluded (wayfinding for instance) which will need further attention before matters of compliance can be concluded. As Beecher (2005) noted the process is slow, particularly when using a consensus approach. However, consensus, is essential if implementation is to be embraced by all parties. Achieving such consensus will be extremely difficult given the diversity of financial, social and ethical interests of the participants. Achieving approval and implementation of the current proposed Premises Standard will be a good start, but it won't consolidate 
into legislation the requirements for wayfinding that this paper raises.

The number of building users with ID is greater than people may realise. As a result, providing access to this group and their associated carers, guardians and friends may, in the long run, prove to be an economic benefit rather than the substantial cost suggested by some. Hopefully, wayfinding will eventually be introduced into the Premises Standard and associated BCA and hopefully this will take into consideration the needs of those with ID. However, the lack of evidencebased research means designers may not understand what they need to do to provide appropriate access. Interestingly though, previous case studies have shown that, when asked, people with ID have described a whole range of issues that affect their use of a building. The first steps to ensuring equitable access, therefore, must be to ask and to listen.

\section{REFERENCES}

Anonymous (2001), 'Village refuge', The Architectural Review; Academic Research Library, vol. Dec, p. p76.

Australian Building Codes Board (2004a), Disability Standards for Access to Premises - Draft Regulation Impact Statement (RIS2004) February 2004 ABCB.

Australian Building Codes Board (2004b), Draft Guidelines to the Disability Standards for Access to Premises (Buildings), ABCB. http://www.abcb.gov.au/index.cfm?objectid =D936FB87-9E9E-FB09-

BA00C0E7AB458047.

Australian Bureau of Statistics (2004), Disabilities, Ageing and Carers, Australia: Disability and Long Term Health Conditions, cat. no. 4430.0.55.001 ABS, Canberra.

Australian Property Council (2004), Comment on the Access to Premises RIS. Retrieved 29 February 2008, from http://www.propertyoz.com.au/data/advoca cy/disability\%20access/a_disability.htm

Beecher, G (2005), 'Disability standards: the challenge of achieving compliance with the Disability Discrimination Act', Australian Journal of Human Rights, vol. 11, no. 1.

Castell, L (2006), 'Building Access for the Intellectually Disabled: A Preliminary Study ', Conference Proceedings AUBEA
2006, University of Technology Sydney, Australia.

Commonwealth Government of Australia (1992), 'Disability Discrimination Act 1992 (as amended up to Act 86 of 2005)', Australia, 5 November 1992.

CRC for Construction Innovation (2007), Wayfinding design guidelines. Retrieved 22 January 2008, from http://www.constructioninnovation.info/images/pdfs/Publications/In dustry_publications/CRC0002_CRC_Wayf inding_Guidelines.pdf

Disability Rights Commission (2003), Creating an inclusive environment. Retrieved 3 December 2007, from http://83.137.212.42/sitearchive/DRC/librar y/publications/services_and_transport/crea ting_an_inclusive_environm.html

Disability Rights Commission (2004a), Good signs: Improving signs for people with a learning disability. Retrieved 30 November 2007, from http://www.equalityhumanrights.com/Docu ments/Disability/Services/Good\%20signs $\% 20$ Improving $\% 20$ signs $\% 20$ for $\% 20$ people $\% 20$ with\%20a\%20learning\%20disability.d OC

Disability Rights Commission (2004b), NOP Survey on disabled peoples experiences of access to services in Britain Full Report January 2003. Retrieved 30 November 2007, from http://83.137.212.42/sitearchive/DRC/librar $\mathrm{y} / \mathrm{research} /$ services_and_transport/nop_su rvey_on_disabled_people\%20.html

Disability Services Commission (2006), Access Resource Kit: A guide to implementing your Disability Access and Inclusion Plan. Retrieved 16 January 2008, from

http://www.disability.wa.gov.au/dscwr/_ass ets/main/instructional/documents/pdf/ark entire_document_(id_161_ver_2.0.0).pdf

FACS (2008), Better physical access, Department of Family and Community Services, Canberra. Retrieved 21 January 2008, from http://www.facs.gov.au/disability/cds/pubs/ bpa/bpa_index.htm

Fraser, J and Barker, P (2000), Sign Design Guide: $A$ guide to inclusive signage, Sign Design Society and JMU Access Partnership.

Golledge, R (1999), Wayfinding behavior: Cognitive mapping and other spatial 
processes, The John Hopkins University Press, Baltimore, USA., Baltimore.

Golledge, R (2003), 'Human Wayfinding and Cognitive Maps', in M Rockman \& J Steele (Eds), Colonization of Unfamiliar Landscapes: The Archaeology of Adaptation, Routledge, UK, pp. 25-43.

Golledge, R, Parnicky, J and Rayner, J (1979), 'An experimental design for assessing the spatial competence of mildly retarded populations', Social Science and Medicine, vol. 13D, pp. 292-5.

Harker, M and King, N, for the Shirley Foundation (2002), Designing for Special Needs: An architect's guide to briefing and designing options for living for people with learning disabilities, RIBA Enterprises, London.

HREOC (2005), The Disability Discrimination Act and the rights of people with disabilities from http://www.humanrights.gov.au/disability_ri ghts/speeches/2005/abcb.htm

HREOC (2006), Australian Institute of Building Surveyors Conference - Earth, wind, fire and water - engaging the elements. Retrieved 28 November 2007, from

http://www.humanrights.gov.au/disability_ri ghts/speeches/2006/aibs.htm

HREOC (2007), Open letter from Graeme Innes AM Human Rights Commissioner to all Local Government Authorities Retrieved 19 November 2007, from http://www.hreoc.gov.au/disability_rights/b uildings/open0907.htm

HREOC and Marrickville Council (2004), Missed Business - How to attract more customers by providing better access to your business, Human Rights and Equal Opportunity Commission, from http://www.humanrights.gov.au/disability_ri ghts/buildings/missed_business/index.html

Huelat, B (2007), Wayfinding: Design for understanding: A Position Paper for the Environmental Standards Council, The Center for Health Design.

Mencap (2007a), Am I making myself clear? Retrieved 10 December 2007, from http://www.mencap.org.uk/html/publication s/publicationSearchResults.asp

Mencap (2007b), On the move 3 Accessible information. Retrieved 10 December 2007, from http://www.mencap.org.uk/html/publication s/publicationSearchResults.asp
Mitchell, P and Ropar, D (2004), 'Visuospatial Abilities in Autism: A Review', Infant and Child Development, vol. Vol.13, pp. 185-98.

Mondschein, A, Blumenberg, E and Taylor, B (2005), 'Cognitive mapping, travel behavior, and access to opportunity', 85th Annual Meeting of the Transportation Research Board, August 1, 2005.

Nelson, P (2004), 'Signage and Wayfinding for People with Learning Disabilities', Open space - People space: An international conference on inclusive environments, Edinburgh.

Office of the Deputy Prime Minister (2006a), Final report for signage and wayfinding for people with learning difficulties: Building Research Technical Report 6/2005, Department of Communities and Local Government. http://www.communities.gov.uk/publication s/planningandbuilding/finalreport.

Office of the Deputy Prime Minister (2006b), Planning and access for disabled people: a good practice guide, Department for Communities and Local Government, UK Government http://www.communities.gov.uk/documents /planningandbuilding/pdf/156681.

Passini, R, Pigot, H, Rainville, $\mathrm{C}$ and Tetreault, M (2000), 'Wayfinding in a Nursing Home for advanced dementia of the alzheimers' type', Environment and Behavior, vol. 32, no. 5, pp. 684-710.

Passini, R, Rainville, C, Marchand, N and Joanette, Y (1998), 'Wayfinding and dementia: Some research findings and a new look at design', Journal of Architectural and Planning Research, vol. Vol 15, no. No 2, pp. 133-51.

Salmi, P (2007), 'Identifying and evaluating critical environmental wayfinding factors for adults with intellectual disabilities'. University of Minnesota, PhD Dissertation.

Salmi, P, Ginthner, D and Guerin, D (2004), 'Critical factors for accessibility and wayfinding for adults with intellectual disabilities', Designing for the 21st Century III: An International Conference on Universal Design, Rio de Janeiro, Brazil. 